\title{
INVIOLABILITY OF THE PERSON IN CRIMINAL PROCEEDINGS AS A GUARANTEE OF THE NATIONAL SECURITY STRATEGY
}

\author{
Yuriy V. Frantsiforov \\ Saratov State Law Academy, Saratov, Russian Federation
}

\begin{abstract}
Introduction: the national security of the state is caused by the requirement to ensure the inviolability of the person, society and the state from the external and internal threats, including in the field of criminal justice, designed to protect the constitutional rights and freedoms of everyone involved in the criminal process.

The main subject of ensuring the security of citizens in the field of criminal justice is the state, represented by the prosecutor, judge, investigator, body of inquiry and investigator, who are obliged to protect the rights and legitimate interests of persons who have suffered from a crime, as well as to protect the person from illegal and unreasonable criminal prosecution, because the person, his rights and freedoms are the highest social value, and their protection is a direct duty of the state, due to the guarantees of the national security of citizens' rights.

In this regard, the goals of this study are: the disclosure of the content of the legal framework of the national security of the state guaranteeing the inviolability of the person in criminal proceedings; the development of recommendations to improve the international and national criminal procedure legislation and the law enforcement activities within the framework of the legal guarantees to ensure the safety of citizens in criminal proceedings. Methods: the methodological framework for this scientific article is a number of methods of scientific cognition, as well as the general scientific research methods such as dialectical, logical, systemic, structural and functional ones including such specific scientific methods as comparative law, formal legal and other methods. Results: in the article the author defines that the national security is a system of measures that are due to the need to ensure the inviolability of the person, society and the state, not only from external, but from internal threats, in various spheres of life and activity of Russian citizens, including in criminal proceedings. The article analyzes the measures to ensure the inviolability of the person in criminal proceedings when the investigator, prosecutor or court chooses the measures of criminal procedural coercion against the accused, suspect and defendant. Conclusions: as a result of the study, there have been made the recommendations to improve the regulatory framework governing the protection of human and civil rights and freedoms guaranteeing the inviolability of the person in criminal proceedings, as well as to make proposals for amendments to the $\underset{N}{*}$ international and national criminal procedure legislation and law enforcement activities within the framework of the legal guarantees to ensure the safety of partiesto a criminal proceeding.

Key words: national security, inviolability of the person, criminal proceedings, protection of rights and freedoms, guarantees of security of the person in criminal proceedings.
\end{abstract}




\title{
НЕПРИКОСНОВЕННОСТЬ ЛИЧНОСТИ В УГОЛОВНОМ СУДОПРОИЗВОДСТВЕ КАК ГАРАНТИЯ СТРАТЕГИИ НАЦИОНАЛЬНОЙ БЕЗОПАСНОСТИ
}

\author{
Юрий Викторович Францифоров \\ Саратовская государственная юридическая академия, г. Саратов, Российская Федерация
}

Введение: национальная безопасность государства вызвана требованием обеспечения неприкосновенности личности, общества и государства от внешних и внутренних угроз, в том числе в сфере уголовного судопроизводства, призванного защищать конституционные права и свободы каждого вовлеченного в сферу уголовного процесса человека.

Главным субъектом обеспечения безопасности граждан в сфере уголовного судопроизводства является государство в лице прокурора, судьи, следователя, органа дознания и дознавателя, которые обязаны защищать права и законные интересы лиц, потерпевших от преступления, а также осуществлять защиту личности от незаконного и необоснованного уголовного преследования, поскольку человек, его права и свободы являются высшей социальной ценностью, а защита их - прямая обязанность государства, обусловленная гарантиями национальной безопасности прав граждан.

В связи с этим целями настоящего исследования являются раскрытие содержания нормативно-правовой базы национальной безопасности государства, гарантирующей неприкосновенность личности в уголовном судопроизводстве, а также разработка рекомендаций по совершенствованию международного и национального уголовно-процессуального законодательства и правоприменительной деятельности в рамках правовых гарантий обеспечения безопасности граждан в уголовном процессе.

Методы: методологической основой данной научной статьи является ряд методов научного познания, например, такие общенаучные исследовательские методы как диалектический, логический, системный, структурно-функциональный, а также такие частнонаучные методы, как сравнительно-правовой, формальноюридический и другие.

Результаты: в статье автор определяет, что национальная безопасность представляет собой такую систему мер, которые обусловлены необходимостью обеспечения неприкосновенности личности, общества и государства не только от внешних, но от внутренних угроз в различных сферах жизни и деятельности граждан России, в том числе в уголовном судопроизводстве. В статье осуществляется анализ мер обеспечения неприкосновенности личности в уголовном судопроизводстве при избрании следователем, прокурором или судом мер уголовно-процессуального принуждения к обвиняемому, подозреваемому и подсудимому.

Выводы: в результате проведенного исследования даны рекомендации по совершенствованию нормативной базы, регламентирующей охрану прав и свобод человека и гражданина, гарантирующей неприкосновенность личности в уголовном судопроизводстве, а также по внесению предложений о внесении изменений в международное и национальное уголовно-процессуальное законодательство и правоприменительную деятельность в рамках правовых гарантий обеспечения безопасности участников уголовного процесса.

Ключевые слова: национальная безопасность, неприкосновенность личности, уголовное судопроизводство, защита прав и свобод, гарантии безопасности личности в уголовном процессе.

\section{Введение}

Национальная безопасность - это система таких мер, которые обусловлены необходимостью обеспечения неприкосновенности личности, общества и государства не только от внешних, но и от внутренних угроз в различных сферах жизни и деятельности граждан России, в том числе и в уголовном процессе.
В стратегии России на период до 2020 г. установлено, что национальная безопасность представляет собой такое состояние защищенности личности, общества и государства от внутренних и внешних угроз, которое позволяет обеспечить конституционные права, свободы, достойное качество и уровень жизни граждан и их безопасность [7]. 
Национальные интересы России связаны с теми интересами личности, в основе которых находятся конституционные права и свободы, гарантии личной безопасности каждого человека в условиях правового государства, каким является Российская Федерация.

\section{Сущность и гарантии обеспечения безопасности граждан в уголовном процессе}

Главным субъектом обеспечения безопасности граждан является государство, а поскольку человек, его права и свободы являются высшей социальной ценностью, то их защита - прямая обязанность государства, обусловленная в том числе и гарантиями национальной безопасности прав граждан, а потому самое большое значение в обеспечении национальной безопасности граждан принадлежит правовым гарантиям.

В теории права и юридической литературе нет единого суждения о понятии «правовые гарантии». В связи с этим следует рассмотреть вопрос о том, что понимается под «гарантиями» в теории права и как они соотносятся с понятием «национальной безопасности прав граждан». По мнению одних авторов, юридические гарантии - это система условий и средств, закрепленных в действующем законодательстве и направленных на обеспечение прав личности [9, с. 519]. Другие ученые к гарантиям относят не только условия и средства, но и сам порядок правового регулирования, а также принципы права $[8$, c. 28].

Приходим к выводу, что в споре о гарантиях каждый из названных авторов по своему прав, выделив одну из сторон этого понятия.

Так, в словаре русского языка С.И. Ожегова гарантия - это ручательство, порука в чем-нибудь. Гарантировать - значит защитить, обеспечить от каких-либо неожиданностей $[6$, с. 130]. Согласно словарю иностранных слов, понятие «гарантия» возникло от французского глагола garantir - «обеспечивать», «охранять», что связано с поручительством третьего лица в случае неудовлетворительного исполнения своих обязанностей должниками [2, с. 151]. В юридической энциклопедии под конституционными гарантиями понимается средство реализации и защиты гражданами своих прав и свобод. Каждому гарантируется судебная защита прав и свобод от решений и действий (бездействий) органов государственной власти или их должностных лиц [1, с. 120].

Таким образом, мы приходим к выводу, что гарантия - это условие, которое обусловлено обязательством обеспечения, охраны или защиты как непосредственно самих граждан, так и принадлежащих им прав и свобод.

Понятие «гарантии» обычно используется с такими терминами, как законность, безопасность, правопорядок, защита прав и свобод, а следовательно наполняется содержанием, которое вызвано особенностью объекта, нуждающегося в охране и защите.

Вместе с тем истоки системы гарантий обеспечения и защиты прав человека и гражданина основываются на заинтересованности государства в эффективном функционировании его правовых институтов, предназначенных для решения социальных вопросов, в основе которых лежит формула, что высшей ценностью является человек, его права и свободы.

Основным правовым институтом российского общества является государство, принимающее законы и иные правовые акты для организации жизни общества и его правовых отношений, главным из которых является отношение государства с человеком.

На вопрос природы правовых гарантий обращал внимание С.Н. Братусь, понимая под ними само право как таковое, в его многообразных проявлениях [3, с. 78-80].

Таким образом, правовые гарантии - это такие законодательно установленные средства, которые обеспечивают реализацию прав и обязанностей личности, а также неприкосновенность личности, поскольку регулируют правоотношения в обществе и государстве.

Гарантии прав и обязанностей взаимосвязаны с правовыми предписаниями, которые обеспечиваются возможностью использования права и необходимостью исполнения обязанности [5, с. 33-34].

Соотношение правовых гарантий с обеспечением национальной безопасности следует рассматривать в рамках существующих государственных преобразований в разных сферах российского общества, которые обус- 
ловлены правами и законными интересами как государства и общества, так и правами и свободами отдельно взятой личности.

Таким образом, к перечню основных гарантий национальной безопасности государства следует отнести неприкосновенность личности, содержанием которой служат средства, направленные на обеспечение прав и свобод, и меры юридической ответственности.

Особое внимание при обеспечении неприкосновенности личности в уголовном судопроизводстве следует обратить на процедуру привлечения лица к уголовной ответственности, которая связана с уголовным преследованием лиц, обвиняемых в совершении преступления.

Законность и обоснованность привлечения к уголовной ответственности при производстве по уголовному делу вызвана соблюдением формулы - «обвиняемый не считается виновным до тех пор, пока его виновность в совершении преступления не доказана следователем и судом и не установлена приговором суда, вступившим в законную силу».

Принцип презумпции невиновности является одной из самых существенных гарантий неприкосновенности личности в уголовном судопроизводстве, поскольку она отдельно установлена в п. 2 ст. 14 Международного пакта о гражданских и политических правах, в п. 1 ст. 11 Всеобщей декларации прав человека, в п. 2 ст. 6 Европейской конвенции о защите прав человека и основных свобод, в ст. 49 Конституции РФ и ст. 14 УПК РФ. Вместе с тем анализ данных норм, составляющих смысл принципа презумпции невиновности, позволяет высказать замечание по их содержанию с целью совершенствования редакции данных норм. Так, требование ч. 4 ст. 24 УПК РФ позволяет следователю вынести постановление об отказе в возбуждении уголовного дела по нереабилитирующим основаниям, что противоречит п. 1 ст. 49 Конституции РФ. Такого юридического порядка не было даже в УУС 1864 г., где, в соответствии со ст. 529-534 УУС, только Судебная палата могла вынести решение о прекращении уголовного преследования не иначе как по письменному предложению состоящего при ней прокурора.

Вместе с тем требование ч. 4 ст. 24 УПК РФ противоречит не только ч. 1 ст. 49 Кон- ституции РФ, но и п. 1 ст. 11 Всеобщей декларации прав человека, в соответствии с которыми установление виновности лица осуществляется законным порядком путем гласного судебного разбирательства и обеспечения возможности для защиты. Данное правовое требование не позволяет решать вопрос о виновности лица следователем, дознавателем и органом дознания. Следует обратить внимание на необходимость логического совершенствования п. 1 ст. 11 Всеобщей декларации прав человека, дополнив ее после слова защиты словами «...от обвинения, излагаемого во вступившем в законную силу приговоре суда» $[12$, с. 9]. Соблюдение гарантии неприкосновенности личности в уголовном судопроизводстве, в том числе включающей в себя и презумпцию невиновности, вызвано и возможностью принятия решения о прекращении уголовного дела по нереабилитирующему основанию, поскольку лицо виновным в совершении преступления не признано, а потому может «нуждаться» в подтверждении своей невиновности в суде, требуя защиты чести и законных интересов.

Поскольку прекращение уголовного дела в связи со смертью обвиняемого лишает возможности судебного разбирательства и доказывания виновности или невиновности лица, то оно должно трактоваться как несоблюдение государством обязанности обеспечить судебную защиту, поскольку отказывает лицу на доступ к правосудию (ч. 1 ст. 118 Конституции РФ).

Таким образом, решение о прекращении уголовного дела не является заменой приговора суда, а потому не может быть приравнено к актам, устанавливающим виновность обвиняемого в совершении преступления.

Наиболее низким уровнем защищенности в области обеспечения неприкосновенности личности и безопасности прав граждан обладает стадия возбуждения уголовного дела, поскольку на ней лишь создаются правовые отношения лиц, вовлекаемых в уголовное судопроизводство. Этих лиц следует называть участниками, не имеющими уголовно-процессуального статуса, поскольку их права и обязанности не закреплены в уголовно-процессуальном законе, а потому в отношении них не установлены правовые гаран- 
тии, выраженные в нормах международного права, Конституции РФ и принципах уголовного судопроизводства.

К таким лицам следует отнести заявителя и очевидца. Так, заявитель в случае вынесения постановления следователя приобретает статус потерпевшего, а до этого момента он не подлежит допросу как полноправный участник уголовного судопроизводства.

Очевидец также лишен процессуальных прав и приобретает их лишь после вынесения постановления следователя, после чего получает статус свидетеля и необходимые для участника уголовного процесса права, в том числе право являться на допрос со своим адвокатом и ходатайствовать о применении в отношении его мер безопасности.

Таким образом, должны найти разумный баланс частные интересы личности, обусловленные ее неприкосновенностью и безопасностью, и публичный интерес общества и государства, связанный с уголовным преследованием лиц, совершивших преступление.

Пробелы правоотношений участников процесса на стадии возбуждения уголовного дела характеризуются отсутствием нормативных предписаний УПК РФ в отношении участников с неопределенным статусом, которые по этой причине не могут быть обеспечены всеми средствами государственной защиты, в том числе касающихся неприкосновенности и безопасности личности.

Эти пробелы могут быть ликвидированы за счет требований ч. 2 ст. 2 Федерального закона от 20.08.2004 г. № 119-Ф3 «О государственной защите потерпевших, свидетелей и иных участников уголовного судопроизводства», позволяющего использовать меры государственной защиты в отношении заявителя и очевидца преступления [10], которые следует внести в УПК РФ, отнеся очевидца и заявителя к иным участникам процесса и наделив их необходимыми правами и обязанностями.

Для обеспечения прав и свобод одних участников уголовного судопроизводства требуется точное и своевременное исполнение обязанностей других его участников. А потому наравне с процессуальными правами участников процесса для них имеются и опреде- ленные ограничения в виде мер уголовно-процессуального принуждения.

Формулирование возможных целей ограничения основных прав и свобод человека и обсуждение их справедливости являлись одним из важнейших вопросов философии права в течение всех исторических периодов. T. Гоббс в качестве основной цели ограничения прав называл обеспечение безопасности [4, c. 120].

Институт процессуальных ограничений прав и свобод в уголовном процессе служит основой, без которой невозможно осуществлять производство по уголовному делу и гарантировать права и свободы, а также безопасность всех участников уголовного судопроизводства.

Уровень цивилизованности общества обусловлен его отношением к правам человека [11, с. 49], а потому одной из важных составных частей стратегии национальной безопасности является вопрос обеспечения неприкосновенности личности, вовлеченной в уголовное судопроизводство.

Ограничение прав и свобод личности может быть вызвано задержанием подозреваемого, а также применением такой строгой меры пресечения, как заключение под стражу.

Вместе с тем применение мер уголовнопроцессуального принуждения, ограничивающих права и свободы личности, должно быть вызвано исключительными обстоятельствами.

\section{Выводы}

В основе правоотношений участников уголовного процесса лежит условие неприкосновенности личности в уголовном судопроизводстве, которое является гарантом стратегии безопасности участников уголовного судопроизводства, а также его важнейшим принципом, направленным на невозможность уголовного преследования лиц при отсутствии на то установленных УПК РФ оснований, требующих от следователя, прокурора и суда обеспечения законности и обоснованности привлечения их к уголовной ответственности, а также защиту личности от незаконного и необоснованного обвинения, осуждения, ограничения ее прав и свобод. 


\section{СПИСОК ЛИТЕРАТУРЫ}

1. Большая юридическая энциклопедия. - М. : Эксмо, 2007. - 688 с.

2. Большой словарь иностранных слов. - М. : Юнвес, 1999. - 784 с.

3. Братусь, С. Н. Юридическая ответственность и законность / С. Н. Братусь. - М. : Юрид. лит., 1976. $-215 \mathrm{c}$.

4. Гоббс, Т. Сочинения. В 2 т. Т. 2 / Т. Гоббс. М. : Мысль, 1991. - 731 с.

5. Корнуков, В. М. Конституционные основы положения личности в уголовном судопроизводстве / В. М. Корнуков. - Саратов : Изд-во Сарат. ун-та, 1987. - 179 с.

6. Ожегов, С. И. Словарь русского языка / под ред. Н. Ю. Шведовой. - М. : Рус. яз., 1990. - 921 с.

7. Стратегия национальной безопасности РФ до 2020 года // Официальный сайт Президента РФ. Электрон. текстовые дан. - Режим доступа: http:// www.kremlin.ru/supplement/424. - Загл. с экрана.

8. Строгович, М. С. Курс советского уголовного процесса / М. С. Строгович. - М. : Изд-во АН CCP, 1958. $-703 \mathrm{c}$.

9. Теория государства и права. Курс лекций / под ред. Н. И. Матузова, А. В. Малько. - М. : Юристь, 1997. - 672 с.

10. Федеральный закон «О государственной защите потерпевших, свидетелей и иных участников уголовного судопроизводства» от 20 авг. 2004 г. № 119-Ф3 // Российская газета. - 2004. - 25 авг. (№ 3558).

11. Францифоров, Ю. В. Особенности применения мер уголовно-процессуального принуждения в отношении женщин и производства следственных действий с их участием / Ю. В. Францифоров // Вестник Волгоградского государственного университета. Серия 5, Юриспруденция. - 2016. № 2 (31). - С. 49-55.

12. Францифоров, Ю. В. Презумпция невиновности в уголовно-процессуальном доказывании / Ю. В. Францифоров, В. А. Пономаренков, Н. А. Громов // Следователь. - 1999. - № 3. - С. 9.

\section{REFERENCES}

1. Bolshaya yuridicheskaya entsiklopediya [The Great Legal Encyclopedia]. Moscow, Eksmo Publ., 2007.688 p.
2. Bolshoy slovar inostrannykh slov [The Large Dictionary of Foreign Words]. Moscow, Yunves Publ., 1999. 784 p.

3. Bratus S.N. Yuridicheskaya otvetstvennost $i$ zakonnost [Legal Responsibility and Legality]. Moscow, Yurid. lit. Publ., 1976. 215 p.

4. Gobbs T. Sochineniya. V 2 t. T. 2 [Works. In 2 vols. Vol. 2]. Moscow, Mysl Publ., 1991. 731 p. 5. Kornukov V.M. Konstitutsionnye osnovy polozheniya lichnosti $v$ ugolovnom sudoproizvodstve [Constitutional Foundations of a Person's Status in Criminal Proceedings]. Saratov, Izd-vo Sarat. un-ta, 1987. 179 p.

6. Ozhegov S.I. Slovar russkogo yazyka [The Dictionary of the Russian Language]. Moscow Rus. yaz. Publ., 1990. 921 p.

7. Strategiya natsionalnoy bezopasnosti RF do 2020 goda [The National Security Strategy of the Russian Federation until 2020]. Ofitsialnyy sayt Prezidenta RF [The Official Website of the President of the Russian Federation]. URL: http://www.kremlin. $\mathrm{ru} /$ supplement/424.

8. Strogovich M.S. Kurs sovetskogo ugolovnogo protsessa [The Course of the Soviet Criminal Process]. Moscow, Izd-vo AN SSR, 1958.703 p.

9. Matuzova N.I., Malko A.V., eds. Teoriya gosudarstva i prava. Kurs lektsiy [The Theory of State and Law. Course of Lectures]. Moscow, Yurist Publ., 1997. 672 p.

10. Federalnyy zakon «O gosudarstvennoy zashchite poterpevshikh, svideteley i inykh uchastnikov ugolovnogo sudoproizvodstva»' ot 20 avg. 2004 g. № 119-FZ [The Federal Law 'On State Protection of Victims, Witnesses and Other Participants in Criminal Proceedings' of August 20, 2004 No. 119-FL]. Rossiyskaya gazeta, 2004, August 25 (No. 3558).

11. Frantsiforov Yu.V. Osobennosti primeneniya mer ugolovno-protsessualnogo prinuzhdeniya v otnoshenii zhenshchin i proizvodstva sledstvennykh deystviys ikh uchastiem [The Features of Applying the Measures of Criminal Procedural Coercion Against Women and the Investigative Activities with Their Participation]. Vestnik Volgogradskogo gosudarstvennogo universiteta. Seriya 5, Yurisprudentsiya [Science Journal of Volgograd State University. Jurisprudence], 2016, no. 2 (31), pp. 49-55.

12. Frantsiforov Yu.V., Ponomarenkov V.A., Gromov N.A. Prezumptsiya nevinovnosti v ugolovnoprotsessualnom dokazyvanii [Presumption of Innocence in Criminal Procedural Proof]. Sledovatel, 1999, no. 3, p. 9. 


\section{Information about the Author}

Yuriy V. Frantsiforov, Doctor of Sciences (Jurisprudence), Professor, Department of Criminal Procedure, Saratov State Law Academy, Chernyshevskogo St., 104, 410056 Saratov, Russian Federation, franciforov@mail.ru.

\section{Информация об авторе}

Юрий Викторович Францифоров, доктор юридических наук, профессор кафедры уголовного процесса, Саратовская государственная юридическая академия, ул. Чернышевского, 104, 410056 г. Саратов, Российская Федерация, franciforov@mail.ru. 